\title{
Upregulation of microRNA-125b-5p is involved in the pathogenesis of osteoarthritis by downregulating SYVN1
}

\author{
FENG-XIAO GE, HAITAO LI and XIN YIN \\ Department of Orthopedics, The People's Hospital of Linyi, Linyi, Shandong 276000, P.R. China
}

Received June 5, 2016; Accepted October 31, 2016

DOI: $10.3892 /$ or.2017.5475

\begin{abstract}
Osteoarthritis (OA) is a degenerative disease characterized by deterioration of articular cartilage. The aim of this study was to identify and characterize the expression of microRNA-125b-5p (miR-125b-5p) in normal and OA synovial cells, and to determine its role in OA pathogenesis. First, the levels of miR-125b-5p and synoviolin 1 (SYVN1) were detected among normal, mild OA and severe OA groups with the use of quantitative PCR. Computational analysis was used to search for the target of the miR-125b-5p, and luciferase reporter assay system was used to validate SYVN1 as the target gene of miR-125b-5p. Then the SYVN1 expression level of cells transfected with miR-125b-5p mimics or inhibitors was estimated using quantitative PCR and western blotting. Finally, MTT assay was employed to estimate the effect of miR-125b-5p on apoptosis. We enrolled 36 participants consisting of 12 normal control, 12 mild OA and 12 severe OA, furthermore, we performed quantitative PCR to detect the levels of miR-125b-5p and SYVN1 among those groups, and found that miR-125b-5p was expressed at highest level in severe OA compared with normal control and mild OA groups, while SYVN1 was expressed at the lowest level in severe OA. Additionally, we identified that SYVN1 is a target of miR-125b-5p by using computational analysis and luciferase assay. Transfection with miR-125b-5p mimic or inhibitor was employed to investigate the effect of miR-125b-5p on expression of SYVN1 in synovial cells, and synovial cell viability and apoptosis, and the results showed that miR-125b-5p mimics significant decreased the expression of SYVN1, a substantially promoted apoptosis of synovial cells, while miR-125b-5p inhibitors remarkably increased the level of SYVN1, and substantially suppressed apoptosis of synovial cells. The data suggested that miR$125 \mathrm{~b}-5 \mathrm{p}$ promoted apoptosis of synovial cells through
\end{abstract}

Correspondence to: Dr Xin Yin, Department of Orthopedics, The People's Hospital of Linyi, 7 Jiefang Road, Linyi, Shandong 276000, P.R. China

E-mail: syvn1oa@126.com

Key words: microRNA-125b-5p, osteoarthritis, synoviolin 1, apoptosis targeting SYVN1 gene, with important implication for validating miR-125b-5p as a potential target for OA therapy.

\section{Introduction}

As a complex disorder with the whole synovial joint involved, osteoarthritis (OA) has the highest prevalence in all forms of arthritis worldwide and contributes to the majority of disability because of pain (1). The knee is the most commonly affected joint and OA often takes place in older adults especially in women (1). It is estimated that there are nearly 27 million adults suffering from OA in 2008 in the USA alone (2). Consequently, it is necessary to carry out remarkable efforts to look into the pathogenesis and pursue better understanding of OA progression and development, which might result to the development of promising treatment regimens.

It has been demonstrated that apoptosis of synovial cells is under control of variable factors, and dysregulation of apoptosis contributes to the development of OA (3-5). It has been reported that significant concentrations of nitric oxide (NO) metabolites, which is believed to promote apoptosis, in human OA synovial fluids $(6,7)$. Apoptotic cells were reported to be present in the synovial membrane in OA as well as in RA. As a result, apoptosis might act as a regulatory event to control metabolism of synovial cells in OA (8).

Recently, synoviolin 1 (SYVN1) expression is highly related to rheumatoid arthritis development and has been confirmed as a rheumatoid regulator. Transgenic SYVN1 mice with high SYVN1 expression had spontaneous arthroplasty, however, mice with reduced SYVN1 (SYVN1+/- mice) were at lower risk of developing collagen-induced arthritis (CIA) (9).

As a class of small, non-coding RNAs, microRNA (miRNA) plays critical roles in development of numerous kinds of species and frequently participates in numerous genetic diseases, including cancer (10). Generally, microRNAs are involved in gene expression downregulation by targeting mRNAs (11). It is believed that a common mechanism of microRNA biogenesis is shared in mammals (12). The primary microRNAs (pri-microRNAs) are transcribed from the genome, followed by processed into precursor microRNAs (pre-microRNAs) in the nucleus by the Microprocessor complex of Drosha (a type of RNase III enzyme) and its cofactor DGCR8 (also named as Pasha) $(13,14)$. A typical hairpin structure consisting of approximately 60-70 nucleotides which is characterized by an 
overhang of approximately 2 nucleotides at the $3^{\prime}$ end exist in pre-microRNAs (15).

Increasing evidence demonstrates that miRNAs play important roles in controlling numerous basic cell functions. miRNAs play key roles in all cellular processes including cartilage remodeling and chondrogenesis (16-18). Consequently, aberrant expression profiles of miRNA was related to development of osteoarthritis (19-22). Previous research has identified a signature of 16 miRNAs which could discriminate normal osteoarthritic cartilage tissue, with 7 miRNAs downregulated and 9 miRNAs remarkably upregulated in osteoarthritis tissue by contrast to normal controls (20).

In a recent study, miR-125b-5p was shown to be upregulated in the Synovial cells collected from OA, and SYVN1 was found to be involved in the pathogenesis of OA (23-25). We identified SYVN1 as a virtual target of miR-125b-5p by using in-silico analysis. In this study, we validated SYVN1 as a target of miR$125 b-5 p$ and tested the role of miR-125b-5p and SYVN1 in the development of OA.

\section{Materials and methods}

Samples. Human synovial cells were isolated from synovium obtained from joint surgery, and synovium was isolated from 36 participants consisting of 12 normal control (K/L, Grade 0: normal cartilage), 12 mild OA (K/L Grade I and II: low grade OA cartilage) and 12 severe OA (K/L, Grade III and IV: high grade OA cartilage) at Department of Orthopedics, The People's Hospital of Linyi (Linyi, China). Trypsin and collagenase were used to digest the superficial layer of synovium after dissection. The protocol of the study was approved by the Ethics Committee of The People's Hospital of Liny. The patients signed informed consent for participation in the study after the potential risk was explained. The study was conducted according to the Declaration of Helsinki.

Synovial cells culture and transfection. DMEM (Dulbecco's modified Eagle's medium) (Gibco ${ }^{\circledR}$ Invitrogen, Carlsbad, CA, USA) containing $100 \mathrm{U} / \mathrm{ml}$ streptomycin, $100 \mathrm{U} / \mathrm{ml}$ penicillin and $10 \%$ FBS (fetal bovine serum) (Hyclone, Logan, UT, USA) was used to culture the synovial cells under a humidified atmosphere of $5 \% \mathrm{CO}_{2} / 95 \%$ air at $37^{\circ} \mathrm{C}$. Lipofectamine 2000 (Invitrogen) was used to perform the transfection in accordance with the manufacturer's instructions. Briefly, when the cells were grown to $80 \%$ confluence, the cells were transfected with miR-125b-5p mimics or inhibitors and scramble control (RiboBio, Guangzhou, China).

Quantitative PCR. The miRNANeasy Mini kit (Qiagen, Hilden, Germany) was used to isolate total RNA from synovial cells and tissue samples in accordance with manufacturer's guideline. Beckman DU-640 spectrophotometer (Beckman Instruments Inc., Fullerton, CA, USA) was used to determine the concentration of RNA extracted following the standard protocol by the supplier, and then $1 \%$ formaldehyde agarose gel electrophoresis was used to evaluate quality of RNA. The quantification of miR-125b and SYVN1 mRNA expression was performed using Applied BiosystemsTaqMan MicroRNA Reverse Transcription kit (Thermo Fisher Scientific, Waltham, MA, USA), TaqMan MicroRNA Assay kits was used to perform the reverse transcription of complementary DNA in accordance with manufacturer's recommendations. Applied Biosystems StepOne Real-Time PCR System (Thermo Fisher Scientific) was used to carry out qRT-PCR (quantitative polymerase chain reaction) following the guideline by the supplier. The protocol of the reaction was carried out at 40 cycles of $95^{\circ} \mathrm{C}$ for $15 \mathrm{sec}, 15 \mathrm{sec}$ at $60^{\circ} \mathrm{C}$, and $30 \mathrm{sec}$ at $70^{\circ} \mathrm{C}$. The Comparative CT (2- $\Delta \Delta \mathrm{Ct})$ method was used to calculate the expression of miR-125b and SYNV1 mRNA. Three independent experiments were performed.

Luciferase assay. PCR (polymerase chain reaction) was used to amplify the human SYVN1 cDNA containing a putative target site for miR-125b-5p. Then the PCR products were inserted into the pGL3 control vector (Promega, Madison, WI, USA) immediately downstream of the stop codon of the firefly luciferase gene (pGL3-SYVN1 -3'UTR). The Quik Change II Site-Directed Mutagenesis kit (Stratagene, La Jolla, CA, USA) was used to generate the mutated version of the $3^{\prime} \mathrm{UTR}$ including a 7-bp mutation (3' mutant). Lipofectamine 2000 (Invitrogen) was used to transiently co-transfect miR-125 mimics and the mutant or wild-type reporter plasmid with the 3'UTR of SYVN1. The dual-luciferase assay kit (Promega) was used to measure the activities of both the Renilla luciferases and firefly 24-48 $\mathrm{h}$ after transfection. Three independent experiments were repeated.

Cell proliferation assay. MTT [3-(4,5-dimethylthiazol-2-yl)2,5-diphenyltetrazolium bromide] assay was used to perform the cell proliferation. The synovial cells were cultured in 48 -well plates, and then $20 \mu \mathrm{l}$ of MTT $(5 \mathrm{mg} / \mathrm{ml})$ was added into each well 1,2, 3 days after trancfection, and the supernatant was removed. DMSO $(150 \mu \mathrm{l})$ was used to dissolve the remaining crystals. A microplate reader was employed to measure the optical density of the cells based on the absorption at $490 \mathrm{~nm}$. Each test was repeated in triplicate.

Western blot analysis. Synovial cells were harvested and washed twice with cold PBS. Radio immune precipitation assay lysis buffer (Invitrogen) was used to lyse the cells according to the protocol, and then centrifuged the cell lysates at $12,000 \times \mathrm{g}$ at $4^{\circ} \mathrm{C}$ for $10 \mathrm{~min}$ to obtain the supernatants contained in the whole-cell protein extracts. DC protein assay (Bio-Rad, Berkeley, CA, USA) was used to determine the concentration of proteins. The protein was treated with boiling water with loading buffer to obtain heat-denatured protein samples, and 10\% SDS-PAGE (poly-acrylamide gel electrophoresis) was used to separate the protein, and then transferred to an Immobilon-P membrane (Millipore, Bedford, MA, USA) for $2 \mathrm{~h}(120 \mathrm{~V})$. PBS containing $0.1 \%$ Tween-20 and $5 \%$ no-fat dry milk was used to incubate the membrane for $1 \mathrm{~h}$ to avoid non-specific binding. The primary antibody antiSYVN1 (1:1000 dilution, Alomone labs Ltd., Jerusalem, Israel) anti- $\beta$-actin (1:8000, Sigma-Aldrich Co., LLC, St. Louis, MO, USA) were used to incubate the membrane at room temperature for $60 \mathrm{~min}$, and washed twice with PBS including $0.1 \%$ Tween-20, and then a secondary antibody (1:15000 dilution, Invitrogen) was used to treat the membrane for another $60 \mathrm{~min}$, and finally washed twice with PBS including 0.1\% Tween-20. Enhanced chemiluminescence detection reagents (Amersham 


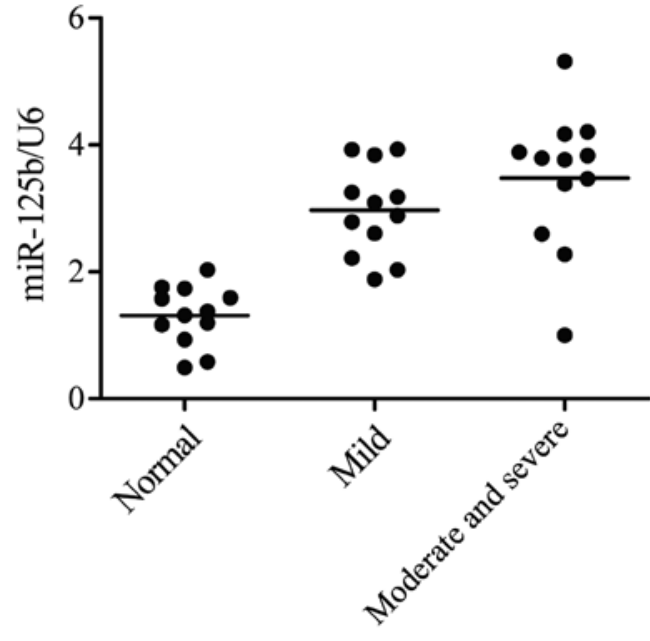

Figure 1. Quantitative PCR was performed to detect the expression level of miR-125b-5p among normal control, mild OA and severe OA groups. The level of miR-125b-5p is the highest in severe OA group.

Biosciences) was used to detect the bound antibody in accordance with manufacturer's protocol.

Apoptosis analysis. BioVision Annexin V-FITC reagent kit (Sigma-Aldrich) and flow cytometry were used to perform apoptosis analysis in accordance with the manufacturer's instruction. At $48 \mathrm{~h}$ after transfection, the synovial cells were trypsinised, and PBS was used to wash the cells, and then the cells were collected by centrifugation of $2000 \mathrm{rpm} / \mathrm{min}$, $5 \mathrm{~min}$, then $5 \mu \mathrm{l}$ propidium iodide, $5 \mu \mathrm{l}$ Annexin VFITC and $500 \mu 1$ binding buffer was added into each well, and incubated for 5-15 min. Finally, flow cytometry was used to estimate the apoptosis of the cells. Three independent tests were performed.

Statistical analysis. Statistical Package of Social Science Software program (SPSS), version 21 (SPSS Inc., Chicago, IL, USA) was used to statistically analyze the data. The data are shown as the means \pm SD (standard deviation) unless otherwise indicated. Independent sample t-test was used to analyze the quantitative variables comparison between groups, and Pearson's Chi-square test was used to analyze qualitative variables comparison between groups. P-value $<0.05$ was considered to indicate a statistically significant difference.

\section{Results}

Expression of miR-125b-5p in normal control, mild OA and severe OA groups. A total of 36 participants were enrolled which consist of 12 normal control (K/L, Grade 0: normal cartilage), 12 mild OA (K/L Grade I and II: low grade OA cartilage) and 12 severe OA (K/L, Grade III and IV: high grade OA cartilage) according to a Kellgren/Lawrence Criterion, cells were cultured, followed by the detection of the gene level using quantitative PCR (qPCR) technique. As shown in Fig. 1, the gene level of miR-125b-5p in severe OA group was the highest in the three groups, while the gene level of miR-125b-5p in normal group was the lowest in the three groups. The data thus indicated that the overexpression level

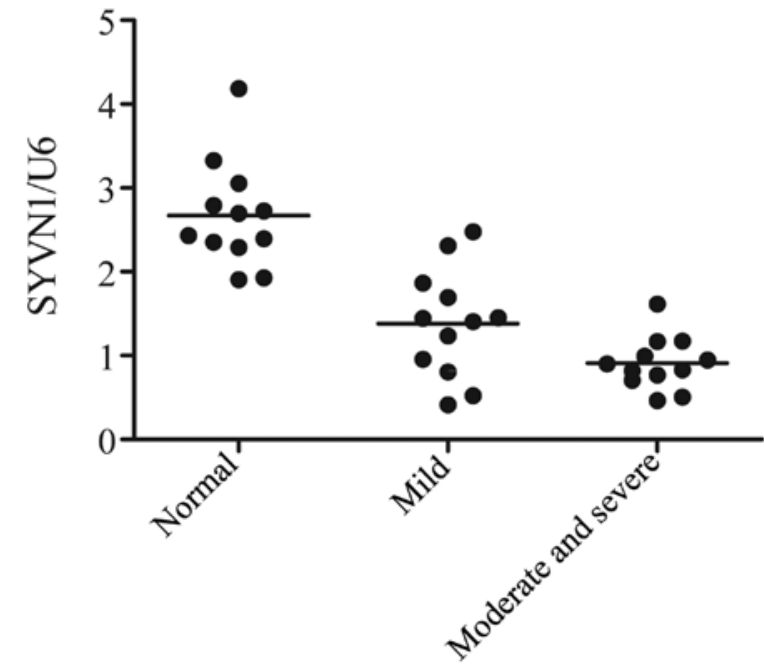

Figure 2. Quantitative PCR was performed to detect the expression level of SYVN1 among normal control, mild OA and severe OA groups. The level of SYVN1 is the lowest in severe OA group.

of miR-125b-5p induce the development of OA, and increased at high grade OA groups, while it decreased at low grade OA group, compared with normal control groups.

Expression of SYVN1 in normal control, mild OA and severe OA groups. The level of SYVN1 was detected with the use of quantitative PCR (qPCR) technique. As shown in Fig. 2, the gene level of SYVN1 in severe OA group was the lowest in the three groups, while the gene level of SYVN1 in normal group was the highest in the three groups. The data thus indicated that the downregulation of SYVN1 induce the development of OA.

miR-125b-5ptargets SYVN1 in synovial cells. By using computational analysis, such as Diana-MICROT, miRDB, TargetMiner, and TargetScan, were chosen to determine the possible target genes of miR-125b-5p, we identified that SYVN1 is a virtual target of miR-125b-5p with binding sites in the 3'UTR of the gene, as shown in Fig. 3. To further confirm the interaction between SYVN1 3'TUR and miR-125b-5p, we sub-cloned the full length SYVN1 3'UTR into a vector and co-transfected it with miR-125b-5p mimics or inhibitors prior to dual-luciferase analysis, and we found that the luciferase activity of the cells cotransfected with wild-type SYVN1 3'UTR was significantly lower than that of the cells transfected with mutant SYVN1 3'UTR and scramble controls, while the luciferase activity of the cells transfected with mutant SYVN1 3'UTR was substantially comparable with that of the cells transfected with scramble controls (Fig. 4), indicating that the SYVN1 was the target gene of miR-125b-5p, and the upregulation of miR-125b-5p suppressed the expression of SYVN1.

Negative regulatory relationship between SYVN1 and miR$125 b-5 p$. The regulatory relationship between SYVN1 and miR-125b-5p was tested with the use of quantitative PCR, as shown in Fig. 5, the negative regulatory relationship between miR-125b-5p and SYVN1 was validated, and the negative correlation coefficient was $-0.40(r=-0.40)$. 
A Wild-type SYVN1

hsa-miR-125b-5p

Mutant SYVN1

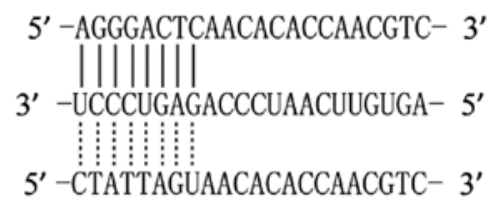

B Human SYVN1 mRNA

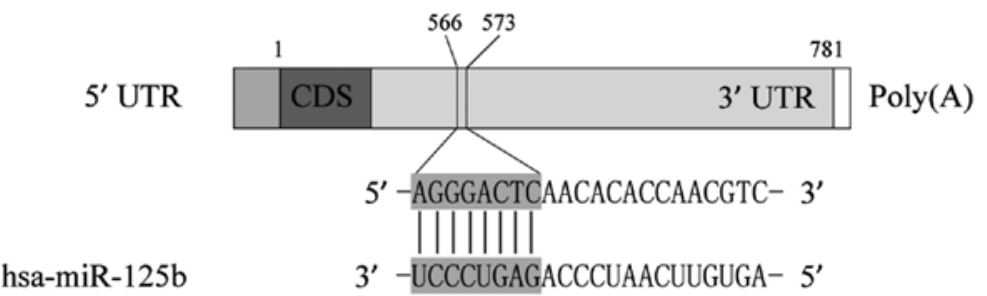

Figure 3. (A) Based on computational analysis, SYVN1 may be the target of miR-125b-5p. (B) The schematic shows that the 3' UTR of SYVN1 contains the miR-125b-5p seed sites.

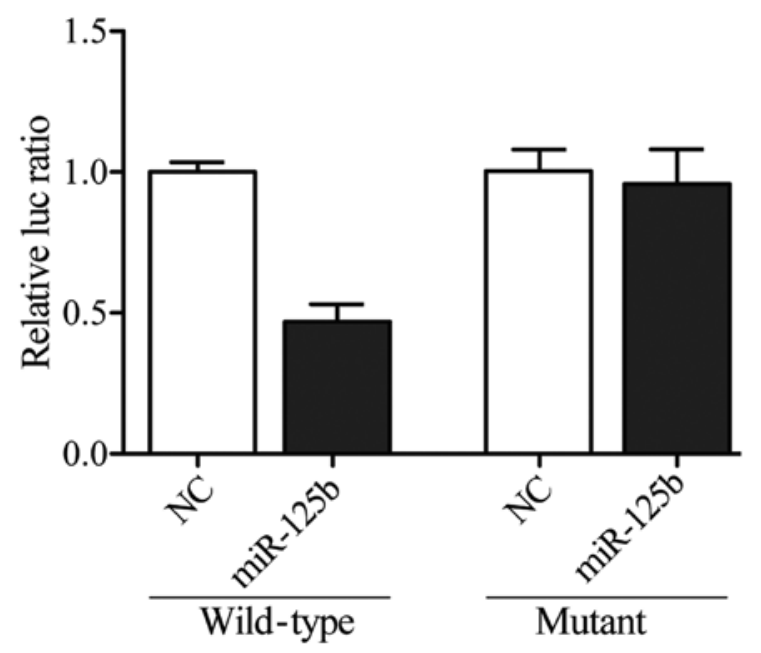

Figure 4. Cells were transiently co-transfected with the wild-type SYVN1 3' UTR or mutant SYVN1 3' UTR, respectively. The cells were harvested at $48 \mathrm{~h}$ after transfection, and then luciferase activity were measured by dualluciferase reporter assay.

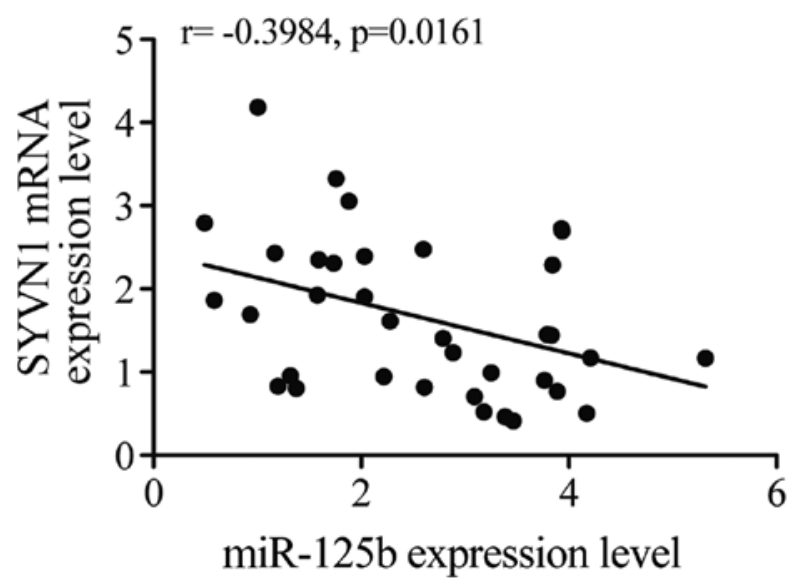

Figure 5. The expression level of SYVN1 mRNA and the expression of miR-125b-5p were measure by quantitative PCR to comfirm miRNA-mRNA regulatory relationship. We validated the negative regulatory relationship between miR-125b-5p and SYVN1, and the negative correlation coefficient was $-0.40(r=-0.40)$.
Overexpression of miR-125b-5p decreases expression of SYVN1. To investigate whether miR-125b-5p has an inhibitory effect on the expression of SYVN1, quantitative PCR and western blot analysis were used. Cells were transfected with miR-125b-5p mimic, miR-125b-5p inhibitor and scramble control in synovial cells, respectively. As showed in Fig. 6, both mRNA (Fig. 6A) and protein (Fig. 6B) SYVN1 expression were significantly decreased in cells in which miR-125b-5p was overexpressed (transfected with miR-125b-5p), in comparison with similar cells transfected with scramble control. On the other hand, downregulation of miR-125b-5p via transfection of the cells with miR-125b-5p inhibitors significantly upregulated the mRNA (Fig. 6A) and protein (Fig. 6B) expression of SYVN1. These findings further demonstrated that SYVN1 is a direct target of miR-125b-5p in PTENCE cell lines.

Effect of miR-125b-5p on proliferation and apoptosis of synovial cells. As synovial cells apoptosis and proliferation are crucial elements in OA pathogenesis, the effect of miR$125 \mathrm{~b}-5 \mathrm{p}$ on synovial cell apoptosis and proliferation were investigated using CCK8 assay. The results of CCK8 assay showed that miR-125b-5p mimic inhibited cell proliferation of OA synovial cells (Fig. 7A), In contrast, miR-125b-5p inhibitor promoted cell proliferation of OA synovial cells at the same time (Fig. 7A) compared with scramble control. Moreover, to explore the underlying molecular mechanisms, we evaluated the apoptosis status of the differently treated synovial cells, and found that overexpression of miR-125b-5p promotes apoptosis of synovial cells, while downregulation of miR-125b-5p significantly inhibits apoptosis of synovial cells. These data suggested that proliferation was inhibited and apoptosis was promoted by miR-125b-5p.

\section{Discussion}

Previously, miR-125b-5p was demonstrated to be involved in atherosclerosis, at least partially, for the first time by signaling for adhesion molecules and inflammatory cytokines which participated in vascular atherosclerosis pathological process. miR-125b-5p was also reported to be reduced during vascular neointima formation and in calcified vessels in atherosclerotic 


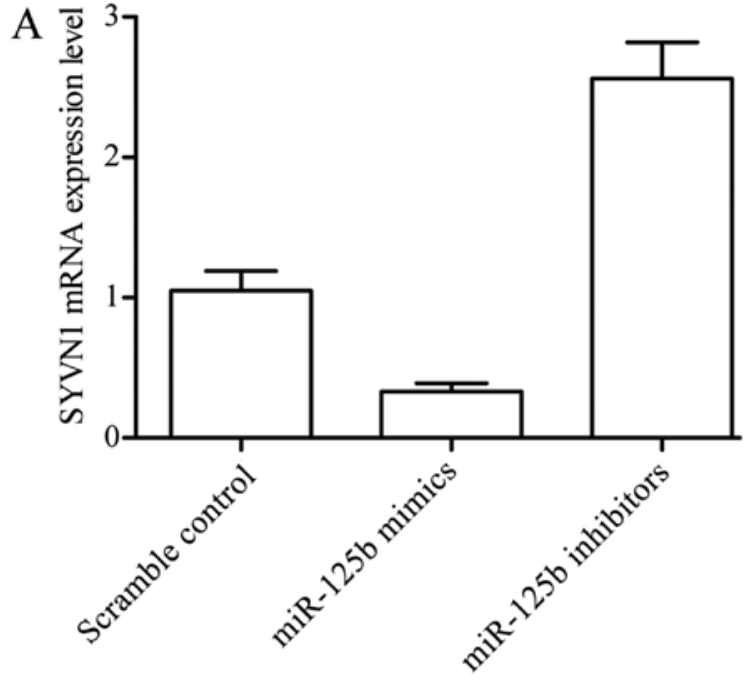

B

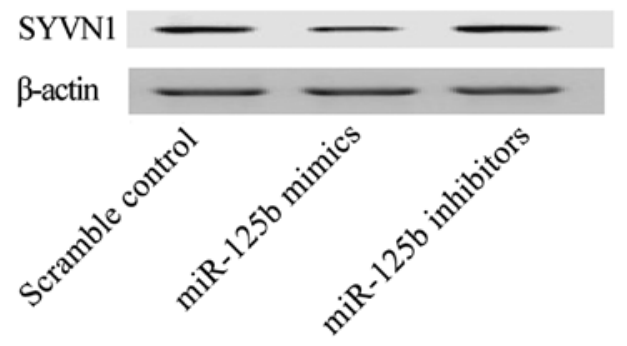

Figure 6. (A) The level of SYVN1 protein of cells transfected with miR$125 \mathrm{~b}-5 \mathrm{p}$ mimics was much lower than scramble control, while notably higher subsequent to transfection with miR-125b-5p inhibitor. (B) The level of SYVN1 mRNA of cells transfected with miR-125b-5p mimics was much lower than scramble control, while notably higher following introduction of miR-125b-5p inhibitor.

mice by Goettsch et al (26), and Tili et al (27) reported that the expression level of MCP-1 and IL- 6 was decreased by miR$125 \mathrm{~b}-5 \mathrm{p}$ overexpression, which agreed with their previous research results showing that expression level of miR-125b-5p reduced in response to tumor necrosis factor- $\alpha$ and lipopolysaccharide. Those findings suggested that miR-125b-5p might serve as a small molecular target during atherosclerosis. Moreover, the data indicated that exertion of miR-125b-5p function might be related to inflammation $(28,29)$.

It has been demonstrated previously that miR-125b-5p served as a leukemogenesis oncomiR (30). The chief carcinogenic event is miR-125b activation by the chromosomal translocation $\mathrm{t}(2 ; 11)(\mathrm{p} 21 ; \mathrm{q} 23)$ in acute myeloid leukemia and miR-125b locus translocation into immunoglobulin heavy chain enhancer in lymphoblastic leukemia $[\mathrm{t}(11 ; 14)$ (q24;q32)] $(31,32)$ Targeting to multiple genes such as STAT3, PUMA, BCL3 and BAK1, miR-125b-5p was involved in apoptosis regulation, however, miR-125b-5p could lead to either tumor suppression or oncogenesis depending on cell types (30). miR-125b-5p overexpression leads to apoptosis in the majority of myeloma cells, resulting in survival benefit in T-ALL (33-35).

In this study, we collected 36 participants consisting of 12 normal control, 12 mild OA and 12 severe OA samples based on the Kellgren/Lawrence Criterion prior to our research, then we performed quantitative PCR on the expression levels of miR-125b-5p and synoviolin 1 (SYVN1) among the three
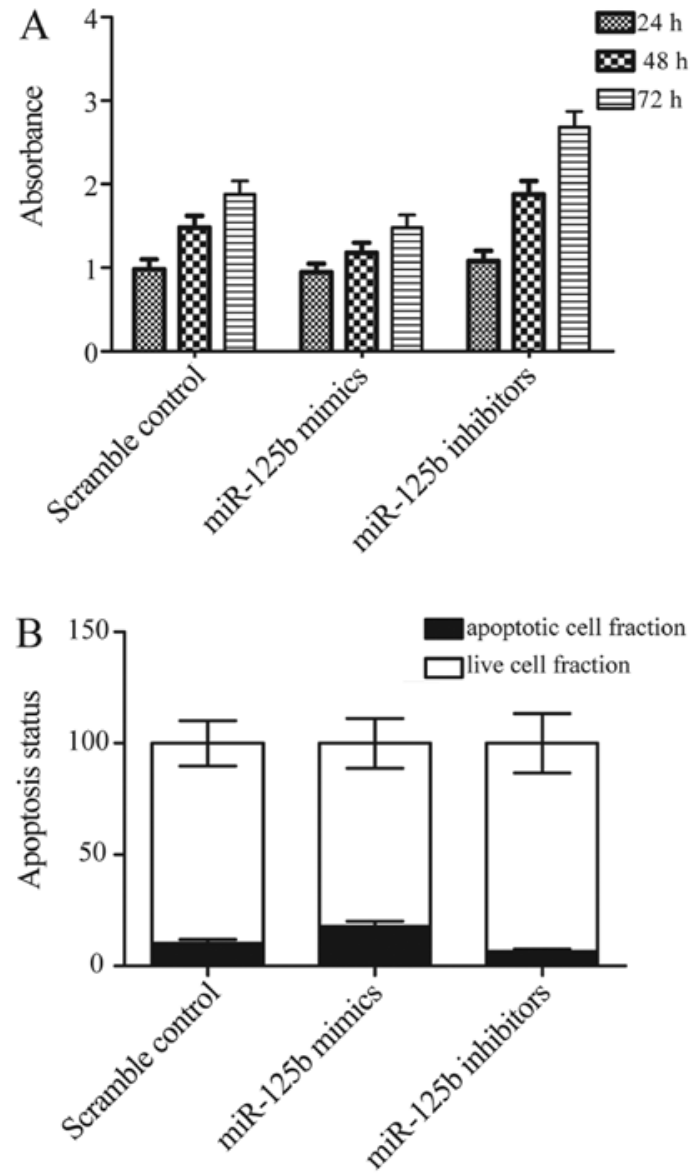

Figure 7. The proliferation rate of and apoptosis of cells were measured by CCK-8 assay as described in Materials and methods. (A) The proliferation of cells transfected with miR-125b-5p mimics was reduced, while promoted when transfected with miR-125b-5p inhibitor. (B) Overexpression of miR-125b-5p promotes apoptosis of synovial cells, while downregulation of miR-125b-5p significantly inhibits the apoptosis of synovial cells.

groups, and found that the gene level of miR-125b-5p in severe OA group was the highest in the three groups, while the gene level of miR-125b-5p in normal group was the lowest. While the gene level of SYVN1 in severe OA group was the lowest, while the gene level of SYVN1 in normal group was the highest in the three groups. Moreover, we then performed computational analysis and luciferase analysis to confirm that SYVN1 is a virtual target of miR-125b-5p with binding sites in the 3'UTR of the gene, and confirmed by the luciferase activity of the cells co-transfected with wild-type SYVN1 3'UTR were significantly lower than that of the cells transfected with mutant SYVN1 3'UTR and scramble controls, while the luciferase activity of the cells transfected with mutant SYVN1 3'UTR substantially comparable with that of the cells transfected with scramble controls.

Synoviolin (SYVN1), the thologue or mammalian of yeast Hrd1 (degradation of 3-hydroxy-3-methylglutaryl reductase) is a multispanning membrane protein, and RING-H2 finger domain in the carboxy-terminal located in the cytoplasm (36). Substantial research has indicated that SYVN1 served as an E3 ubiquitin ligase for endoplasmic reticulum (ER)-associated degradation (ERAD), a process participating in quality control of cells and cellular adaptation to ERAD misfolded proteins $(37,38)$. ERAD is involved in numerous 
human diseases, for example diabetes and neurodegenerative diseases (such as Alzheimer disease, cerebral ischaemia/ hypoxia and Parkinson's disease) (39). In the ERAD pathway, SYVN1 is involved in the harmful protein disposing, ubiquitination and recognition, making sure that these proteins are delivered by ER and degraded to reduce damage of ER. SYVN1 also suppress ER stress-induced apoptosis $(9,40)$.

In this study, we investigated quantitative PCR to confirm the negative regulatory relationship between SYVN1 and miR$125 b-5 p$ based on the negative correlation coefficient $(r=-0.40)$. We then conducted quantitative PCR and western blot analysis to detect the expression level of SYVN1 of cells induced with miR-125b-5p mimics or inhibitors, we found overexpression of miR-125b-5p suppressed the level of SYVN1, while downregulation of miR-125b-5p upregulated the level of SYVN1. Finally, we performed MTT assay to detect the effect of miR$125 \mathrm{~b}-5 \mathrm{p}$ on apoptosis and proliferation of synovial cells by use of CCK8 kit, and found that miR-125b-5p mimic inhibited cell proliferation, and miR-125b-5p inhibitor promoted cell proliferation of OA synovial cells. In contrast, overexpression of miR-125b-5p promoted apoptosis of synovial cells, while downregulation of miR-125b-5p significantly inhibited the apoptosis of synovial cells. SYVN1 was confirmed as a rheumatoid regulator and its expression was significantly related to rheumatoid arthritis development. Spontaneous arthropathy was observed in transgenic SYVN1 mice with SYVN1 overexpression, however, mice with reduced SYVN1 (SYVN1+/- mice) were at lower risk of developing collageninduced arthritis (CIA) $(9,41)$.

In conclusion, these findings demonstrated that miR$125 \mathrm{~b}-5 \mathrm{p}$ could promote apoptosis of synovial cells through targeting the SYVN1 gene, and the excessive apoptosis of synovial cells could contribute to the development of OA.

\section{References}

1. Schaible HG, Richter F, Ebersberger A, Boettger MK, Vanegas H, Natura G, Vazquez E and Segond von Banchet G: Joint pain. Exp Brain Res 196: 153-162, 2009.

2. Lascelles BD, McFarland JM and Swann H: Guidelines for safe and effective use of NSAIDs in dogs. Vet Ther 6: 237-251, 2005.

3. Blanco FJ, Ochs RL, Schwarz H and Lotz M: Chondrocyte apoptosis induced by nitric oxide. Am J Pathol 146: 75-85, 1995.

4. Albina JE, Cui S, Mateo RB and Reichner JS: Nitric oxidemediated apoptosis in murine peritoneal macrophages. J Immunol 150: 5080-5085, 1993.

5. Fehsel K, Kröncke KD, Meyer KL, Huber H, Wahn V and KolbBachofen V: Nitric oxide induces apoptosis in mouse thymocytes. J Immunol 155: 2858-2865, 1995.

6. Farrell AJ, Blake DR, Palmer RM and Moncada S: Increased concentrations of nitrite in synovial fluid and serum samples suggest increased nitric oxide synthesis in rheumatic diseases. Ann Rheum Dis 51: 1219-1222, 1992.

7. Hayashi T, Abe E, Yamate T, Taguchi Y and Jasin HE: Nitric oxide production by superficial and deep articular chondrocytes. Arthritis Rheum 40: 261-269, 1997.

8. Firestein GS, Yeo M and Zvaifler NJ: Apoptosis in rheumatoid arthritis synovium. J Clin Invest 96: 1631-1638, 1995.

9. Amano T, Yamasaki S, Yagishita N, Tsuchimochi K, Shin H, Kawahara K, Aratani S, Fujita H, Zhang L, Ikeda R, et al: Synoviolin/Hrd1, an E3 ubiquitin ligase, as a novel pathogenic factor for arthropathy. Genes Dev 17: 2436-2449, 2003.

10. Esquela-Kerscher A and Slack FJ: Oncomirs - microRNAs with a role in cancer. Nat Rev Cancer 6: 259-269, 2006.

11. Bartel DP: MicroRNAs: Genomics, biogenesis, mechanism, and function. Cell 116: 281-297, 2004.
12. Murchison EP and Hannon GJ: miRNAs on the move: miRNA biogenesis and the RNAi machinery. Curr Opin Cell Biol 16: 223-229, 2004

13. Lee Y, Ahn C, Han J, Choi H, Kim J, Yim J, Lee J, Provost P, Rådmark O, Kim S, et al: The nuclear RNase III Drosha initiates microRNA processing. Nature 425: 415-419, 2003.

14. Denli AM, Tops BB, Plasterk RH, Ketting RF and Hannon GJ: Processing of primary microRNAs by the microprocessor complex. Nature 432: 231-235, 2004

15. Nam JW, Shin KR, Han J, Lee Y, Kim VN and Zhang BT: Human microRNA prediction through a probabilistic co-learning model of sequence and structure. Nucleic Acids Res 33: 3570-3581, 2005.

16. Swingler TE, Wheeler G, Carmont V, Elliott HR, Barter MJ, Abu-Elmagd M, Donell ST, Boot-Handford RP, Hajihosseini MK, Münsterberg A, et al: The expression and function of microRNAs in chondrogenesis and osteoarthritis. Arthritis Rheum 64: 1909-1919, 2012.

17. Hong E and Reddi AH: MicroRNAs in chondrogenesis, articular cartilage, and osteoarthritis: Implications for tissue engineering. Tissue Eng Part B Rev 18: 445-453, 2012.

18. Dong S, Yang B, Guo H and Kang F: MicroRNAs regulate osteogenesis and chondrogenesis. Biochem Biophys Res Commun 418: 587-591, 2012.

19. Dunn W, DuRaine G and Reddi AH: Profiling microRNA expression in bovine articular cartilage and implications for mechanotransduction. Arthritis Rheum 60: 2333-2339, 2009.

20. Iliopoulos D, Malizos KN, Oikonomou P and Tsezou A: Integrative microRNA and proteomic approaches identify novel osteoarthritis genes and their collaborative metabolic and inflammatory networks. PLoS One 3: e3740, 2008.

21. Yu C, Chen WP and Wang XH: MicroRNA in osteoarthritis. J Int Med Res 39: 1-9, 2011.

22. Goldring MB and Marcu KB: Epigenomic and microRNAmediated regulation in cartilage development, homeostasis, and osteoarthritis. Trends Mol Med 18: 109-118, 2012.

23. Crowe N, Swingler TE, Le LT, Barter MJ, Wheeler G, Pais H, Donell ST, Young DA, Dalmay T1 and Clark IM: Detecting new microRNAs in human osteoarthritic chondrocytes identifies miR-3085 as a human, chondrocyte-selective, microRNA. Osteoarthritis Cartilage 24: 534-543, 2016.

24. Yamasaki S, Yagishita N, Tsuchimochi K, Kato Y, Sasaki T, Amano T, Beppu M, Aoki H, Nakamura H, Nishioka K, et al: Resistance to endoplasmic reticulum stress is an acquired cellular characteristic of rheumatoid synovial cells. Int J Mol Med 18: 113-117, 2006.

25. Yagishita $\mathrm{N}$ and Nakajima T: Synoviolin as a causative factor of arthropathy. Tanpakushitsu Kakusan Koso 51 (Suppl 10): 1298-1303, 2006 (In Japanese).

26. Goettsch C, Rauner M, Pacyna N, Hempel U, Bornstein SR and Hofbauer LC: miR-125b regulates calcification of vascular smooth muscle cells. Am J Pathol 179: 1594-1600, 2011.

27. Tili E, Michaille JJ, Cimino A, Costinean S, Dumitru CD, Adair B, Fabbri M, Alder H, Liu CG, Calin GA, et al: Modulation of miR-155 and miR-125b levels following lipopolysaccharide/ TNF-alpha stimulation and their possible roles in regulating the response to endotoxin shock. J Immunol 179: 5082-5089, 2007.

28. Li X, Yao N, Zhang J and Liu Z: MicroRNA-125b is involved in atherosclerosis obliterans in vitro by targeting podocalyxin. Mol Med Rep 12: 561-568, 2015.

29. Luo X, Ranade K, Talker R, Jallal B, Shen N and Yao Y: microRNA-mediated regulation of innate immune response in rheumatic diseases. Arthritis Res Ther 15: 210, 2013.

30. Shaham L, Binder V, Gefen N, Borkhardt A and Izraeli S: MiR-125 in normal and malignant hematopoiesis. Leukemia 26: 2011-2018, 2012.

31. Bousquet M, Quelen C, Rosati R, Mansat-De Mas V, La Starza R, Bastard C, Lippert E, Talmant P, Lafage-Pochitaloff M, Leroux D, et al: Myeloid cell differentiation arrest by miR-125b-1 in myelodysplastic syndrome and acute myeloid leukemia with the $\mathrm{t}(2 ; 11)$ (p21;q23) translocation. J Exp Med 205: 2499-2506, 2008.

32. Chapiro E, Russell LJ, Struski S, Cavé H, Radford-Weiss I, Valle VD, Lachenaud J, Brousset P, Bernard OA, Harrison CJ, et al: A new recurrent translocation $\mathrm{t}(11 ; 14)(\mathrm{q} 24 ; \mathrm{q} 32)$ involving IGH@ and miR-125b-1 in B-cell progenitor acute lymphoblastic leukemia. Leukemia 24: 1362-1364, 2010.

33. Zhang GQ, Kai M, Nakano M and Ohkura Y: Pre-column fluorescence derivatization high-performance liquid chromatography of opioid peptides in rat brain and its use for enzymatic peptide characterization. Chem Pharm Bull (Tokyo) 39: 126-129, 1991. 
34. Schotte D, De Menezes RX, Akbari Moqadam F, Khankahdani LM, Lange-Turenhout E, Chen C, Pieters R and Den Boer ML: MicroRNA characterize genetic diversity and drug resistance in pediatric acute lymphoblastic leukemia. Haematologica 96: 703-711, 2011.

35. Ooi AG, Sahoo D, Adorno M, Wang Y, Weissman IL and Park CY: MicroRNA-125b expands hematopoietic stem cells and enriches for the lymphoid-balanced and lymphoid-biased subsets. Proc Natl Acad Sci USA 107: 21505-21510, 2010.

36. Hampton RY, Gardner RG and Rine J: Role of $26 \mathrm{~S}$ proteasome and HRD genes in the degradation of 3-hydroxy-3-methylglutarylCoA reductase, an integral endoplasmic reticulum membrane protein. Mol Biol Cell 7: 2029-2044, 1996.

37. Gardner RG, Swarbrick GM, Bays NW, Cronin SR, Wilhovsky S, Seelig L, Kim C and Hampton RY: Endoplasmic reticulum degradation requires lumen to cytosol signaling. Transmembrane control of Hrdlp by Hrd3p. J Cell Biol 151: 69-82, 2000.
38. Friedlander R, Jarosch E, Urban J, Volkwein C and Sommer T: A regulatory link between ER-associated protein degradation and the unfolded-protein response. Nat Cell Biol 2: 379-384, 2000.

39. Yoshida H: ER stress and diseases. FEBS J 274: 630-658, 2007.

40. Kaneko M, Ishiguro M, Niinuma $Y$, Uesugi $M$ and Nomura $Y$ : Human HRD1 protects against ER stress-induced apoptosis through ER-associated degradation. FEBS Lett 532: 147-152, 2002.

41. Ritchlin C: Fibroblast biology. Effector signals released by the synovial fibroblast in arthritis. Arthritis Res 2: 356-360, 2000. 